Douglas J Reinhart $M D,{ }^{*}$ Michael E Goldberg $M D,{ }^{\dagger}$ Jonathan V Roth $\mathrm{MD},{ }^{\prime}$ Rita Dua $\mathrm{MD}_{2}^{\ddagger}$ Igal Nevo $\mathrm{MD}^{\ddagger} \ddagger$ Kevin W Klein MD,\$ Marc Torjman M ED, Denis Vekeman CRNA ${ }^{\dagger}$

\section{Transdermal fentanyl system plus im ketorolac for the treatment of postoperative pain}

Purpose: To assess the safety and efficacy of transdermal fentanyl plus im ketorolac vs im ketorolac alone in the treatment of postoperative pain.

Methods: Ninety-two patients scheduled for surgery involving moderate to severe postoperative pain were randomized to one of two groups. Group $A(n=46)$ received an active fentanyl patch and group $P(n=46)$ received a placebo patch. Patches remained in place for $24 \mathrm{hr}$. Each patient received intraoperative ketorolac, $60 \mathrm{mg} \mathrm{im}$. Patients were monitored for $36 \mathrm{hr}$ postoperatively and the groups were analyzed for ketorolac usage. pain scores. vital signs, serum fentanyl concentrations, and adverse events. Intramuscular ketorolac was available on demand.

Results: Group A had lower pain scores at 8,12,16 and $24 \mathrm{hr}$ after patch placement $(P<0.05)$. Group A had lower heart rates, lower respiratory rates and fewer dropouts due to inadequate pain relief $(4.3 \% \mathrm{vs} 21.7 \%$. $P<0.05)$. Group A patients also used less ketorolac than group $P$ patients $(P<0.05)$. The incidence of pruntus was higher in group A patients $(19 \%$ vs $2 \%, P<0.05)$, while the incidence of nausea and vomiting was not different between the two groups. Transdermal fentanyl was adequate "stand-alone" analgesia in only $23.8 \%$ of group A patients while $93.7 \%$ of the remaining group A patients receiving a combination of transdermal fentanyl and ketorolac had adequate pain relief.

Conclusion: The transdermal fentanyl delivery system plus ketorolac im was more effective in controlling postoperative pain than ketorolac im alone. The two treatment modalities were comparable in safety with no difference in serious adverse events.

Objectif : Évaluer en rapport avec le traitement de la douleur postopératoire la sécurité et l'efficacité du fentanyl transdermique associé au kétorolac avec celles du kétorolac seul.

Méthodes : Quatre-vingt-douze patients programmés pour une chirurgie comportant des douleurs postopératoires modérées à graves étaient répartis aléatoirement entre deux groupes. Le groupe $A(n=46)$ recevait un timbre autocollant au fentanyl et le groupe $P(n=46)$ un timbre placebo. Les timbres demeuraient en place pendant $24 \mathrm{~h}$. Chaque patient recevart $60 \mathrm{mg}$ de kétorolac im pendant l'intervention. Les patients étaient gardés sous surveillance pendant $36 \mathrm{~h}$ après l'intervention et la dose de kétorolac utilisée, les scores de douleur, les signes vitaux, les concentrations de fentanyl et les incidents indésirables étaient notés. Du kétorolac était administré im sur demande.

Résultats : Les patients du groupe A présentaient les scores de douleur les plus bas à 8, 12. 16 et $24 \mathrm{~h}$ après l'application du timbre $(P<0,05)$. Les patients du groupe $A$ avaient la fréquence cardiaque et respiratoire la plus lente et le moins de décrochage par insatisfaction $(4,3 \%$ vs $21,7 \% \$, P<0,05)$. Les patients du groupe A ont aussi utilisé moins de kétorolac que ceux du groupe $P(P<0,05)$. L'incidence de prurit était plus élevée chez les patients du groupe $A(19 \%$ vs $2 \%,(P<0,05)$, alors que l'incidence des nausées et des vomissements était la même dans les deux groupes. Le fentanyl transdermique n'était suffisant comme analgésique unique que dans seulement $23.8 \%$ des patients du groupe A; $93.7 \%$ des autres patients du groupe A qui avaient reçu une combinaison de fentanyl transdermique et de kétorolac étaient suffisamment soulagés.

Conclusions : L'administration transdermique de fentanyl associé au kétorolac im a été plus efficace pour soulager la douleur que le kétorolac im seul. Sous l'aspect de la sécurité et des incidents indésirables, les deux méthodes étaient comparables.

${ }^{\star}$ From the Departments of Anesthesiology, University of Utah, ${ }^{\dagger}$ University of Mcdicine and Dentistry of New Jersey, ${ }^{\dagger}$ Temple University School of Medicine $\$$ University of Texas, Southwestern Med Ctr, Dallas, TX, United States and $\$ \star$ Jefferson Medical College, United States Address correspondence to: Douglas J. Reinhart MD, Department of Anesthesiology, McKay-Dee Hospital, 3939 Harrison Blvd, Ogden, Utah 84409.

Supported in part by a grant from Anaquest, Inc.

Accepted for Publication January 12, 1997. 
$\mathrm{T}$

HE currently available transdermal fentanyl system (Duragesic, TTS-Fentanyl, ALZA Corporation, Palo Alto, Calif. marketed by Janssen Pharmaceutica, Piscataway, N.J.) is approved by the FDA in the US for opioid tolerant patients but not for opioid naive patients. Concerns over the use of Duragesic transdermal fentanyl have been raised stemming from its misuse in patients with pain after surgery. Nine case reports of the use of Duragesic transdermal fentanyl in outpatient, minor surgery conditions causing major respiratory depression, arrest and death up to $24 \mathrm{hr}$ later have been investigated by the FDA. ${ }^{1,2}$ These reports and the cause of death are difficult to evaluate because of concurrent analgesic medication and the unsupervised home care. These poor outcomes are of particular concern because the Duragesic transdermal fentanyl was evaluated for use in over 350 opioid naive patients with postoperative pain. The FDA, Alza Corporation and Janssen Pharmaceuticals concluded that there was no effective analgesic dose of the Duragesic system that was also safe in opioid naive patients with postoperative pain and recommended against its use in this population..$^{3-5}$ The development of a new transdermal fentanyl system using different technology (FTDSfentanyl, Cygnus Therapeutic systems, Palo Alto, Calif.) has again raised the question of whether a transdermal fentanyl delivery system may be safe and useful for the management of acute pain. ${ }^{6,7}$ In addition, a number of reports suggested that transdermal fentanyl may be useful and safe in treating acute pain if lower doses were coupled with non-opioid analgesic supplementation, such as nonsteroidal anti-inflammatory drugs, in a monitored medical environment. ${ }^{8,9}$

The purpose of the current study was to determine the safety and efficacy of the FTDS-fentanyl transdermal delivery system for the control of postoperative pain under conditions of general use in the post-surgical patient population. A nonsteroidal anti-inflammatory drug, ketorolac tromethamine, was used as the concomitant analgesic for the fentanyl transdermal system instead of additional opioid analgesia. This multimodal approach has not been examined in previous studies and may, theoretically, reduce the frequency of side effects of opioids without compromising pain relief.

\section{Methods and materials}

The study design was randomized, double-blinded and placebo-controlled. Each of the three centres participating in the study used their own randomization code. Institutional Review Board approval was obtained at each participating institution. After written informed consent was obtained, 92 ASA 1-3 patients undergoing surgery with anticipated moderate to severe postoperative pain (Table I) were randomized to one of two groups. Patients in Group A $(n=46)$ received an active (FTDS) fentanyl patch. If the patient weighed $<60 \mathrm{~kg}$, they received a $30 \mathrm{~cm}^{2}$ patch (FTDS-30) delivering approximately $55-65 \mu \mathrm{g} \cdot \mathrm{hr}^{-1}$ and if $260 \mathrm{~kg}$, they received a $40 \mathrm{~cm}^{2}$ patch (FTDS-40) delivering approximately 70-80 $\mathrm{gg} \cdot \mathrm{hr}^{-1}$. Group P $(\mathrm{n}=46)$ received either a $30 \mathrm{~cm}^{2}$ or a $40 \mathrm{~cm}^{2}$ placebo patch identical in appearance to its active counterpart according to the patient's weight. The patch was placed on the left anterior chest wall two hours before surgery and remained for $24 \mathrm{hr}$ before removal. If necessary, hair was clipped from the patch site prior to application. The area was not shaved to maintain an intact skin so the absorption rate remained unchanged.

Patients with a documented history of opioid or NSAID sensitivity, drug abuse, recent opioid analgesic or angiotensin converting enzyme inhibitor therapy, a history of severe respiratory or neurological symptoms or having an unstable medical condition were excluded from the study as were patients $>110 \mathrm{~kg}$ or $<45 \mathrm{~kg}$, age $\leq 18$ or $>65 \mathrm{yr}$ and ASA status 4 or 5 .

The current study utilized an alternative transdermal patch design (FTDS-fentanyl, CYGNUS Therapeutic Systems, Redwood City, Calif.). ${ }^{6}$ The new Cygnus transdermal fentanyl system is represent-

TABLE I Demographics and Procedures

\begin{tabular}{lcc}
\hline Demographic & Group A & Group P \\
\hline Age* (yr) & $51.4 \pm 12.1$ & $46.5 \pm 11.7$ \\
Weight* $^{*}(\mathrm{~kg})$ & $72.9 \pm 10.2$ & $83.5 \pm 9.1$ \\
Height* (cm) & $163.1 \pm 14.4$ & $160.9 \pm 12.5$ \\
Male & 12 & 15 \\
Female & 34 & 31 \\
Procedures & Group A & GroupP \\
parotidectomy & 1 & 1 \\
laparoscopic cholecystectomy & 1 & 1 \\
open cholecystectomy & 2 & 3 \\
colectomy & {$[1]$} & $7[3]$ \\
mastectomy & 2 & 3 \\
mammoplasty & 0 & 1 \\
open prostatectomy & 3 & 2 \\
Total General Surgery & 15 & 18 \\
abdominal hysterectomy & $12[1]$ & $10[4]$ \\
vaginal hysterectomy & 2 & 1 \\
oophorectomy & 2 & 1 \\
Total Gynaecological Surgery & 16 & 12 \\
lumbar/cervical spine & 7 & $8[2]$ \\
rotator cuff repair & 1 & 3 \\
ORIF fractured ankle & 1 & 0 \\
total knee replacement & 3 & 2 \\
ORIF wrist & 0 & 1 \\
total hip replacement & 3 & $2[1]$ \\
Total Orthopaedic & 15 & 16 \\
Total Procedures & $46[2]$ & $46[10]$ \\
\hline TMean & SEM). [Drop-outs &
\end{tabular}

${ }^{*}$ Mean $\pm($ SEM $)$. [Drop-outs due to inadequate analgesia]. 


\section{Cygnus Transdermal Fentanyl}

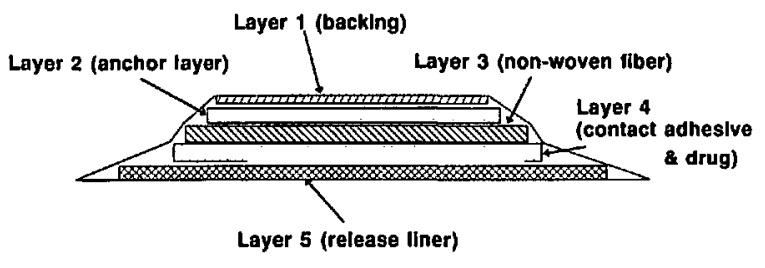

FIGURE 1 Schematic of the FDFP fentanyl patch (CYGNUS Transdermal Systems). The drug is embedded in the contact adhesive layer instead of in a reservoir.

ed schematically in Figure 1. The drug is stored within the fibres of the system and is released transdermally at a steady rate which depends primarily on the patch surface area. The FTDS employs an unsealed multi laminate system containing a solid matrix in which the fentanyl is embedded instead of the reservoir design used in the ALZA system. The biopharmaceutics of the new FTDS system have recently been elucidated. ${ }^{7}$

The subjects underwent the following standard general anaesthetic: premedication with 0.035 $\mathrm{mg} \cdot \mathrm{kg}^{-1}$ midazolam, im or iv, up to a total of $2.5 \mathrm{mg}$, 30-60 min before surgery; induction with 4-6 $\mathrm{mg} \cdot \mathrm{kg}^{-1}$ thiopentone and $0.5-4.0 \mu \mathrm{g} \cdot \mathrm{kg}^{-1}$ sufentanil with $1.5 \mathrm{mg} \cdot \mathrm{kg}^{-1}$ succinylcholine chloride to facilitate tracheal intubation. Maintenance of anaesthesia was with nitrous oxide up to $70 \%$, isoflurane $1-1.3 \%$ and oxygen, $30 \%$. Vecuronium bromide was administered for supplemental neuromuscular blockade and was reversed at the end of the procedure with 40-80 $\mu \mathrm{g} \cdot \mathrm{kg}^{-1}$ neostigmine combined with $8-16 \mu \mathrm{g} \cdot \mathrm{kg}^{-1} \mathrm{gly}-$ copyrrolate. In addition, each patient received an intraoperative loading dose of $60 \mathrm{mg}$ ketorolac tromethamine, $i m$, within $60 \mathrm{~min}$ of the end of the procedure. There was no further administration of sufentanil after the initial dose of ketorolac.

Upon entering the Post Anesthesia Care Unit (PACU), if the patient complained of pain, they were allowed to receive up to $35 \mu \mathrm{g} \cdot \mathrm{kg}^{-1}$ morphine iv and repeated as needed in $\mathbf{1 5} \mathrm{min}$, up to a total dose of 70 $\mu \mathrm{g} \cdot \mathrm{kg}^{-1}$. Thereafter, administration of all analgesics was restricted except for ketorolac im. Supplemental pain control consisted of injectable ketorolac, $30 \mathrm{mg}$ im, every six hours as needed, according to manufacturer's guidelines. If the patient needed additional opioid analgesic, they were discontinued from the study. Also, oxygen was administered at $3 \mathrm{~L} \cdot \mathrm{min}^{-1}$ nasally for the duration of the PACU stay as per standard post-anaesthesia protocol.
Postoperative evaluations were performed by a research nurse or investigator. Patients were evaluated immediately in the recovery room, at $60 \mathrm{~min}$ and at 4 , $8,12,16,24$, and $36 \mathrm{hr}$ after patch placement. Evaluations included noninvasive blood pressure, respiratory rate, heart rate, oxygen saturation by pulse oximetry, and pain. A $100 \mathrm{~mm}$ visual analog scale pain score was used with 0 defined as "no pain" and 100 defined as "worst possible pain." As a standard, pain evaluations were typically done at rest and not immediately after exertion postoperatively.

Patients were monitored for adverse events, including itching, muscle rigidity, hypertension (DBP >90 $\mathrm{mmHg}$ ), hypotension (DBP $<50 \mathrm{mmHg}$ ), tachycardia (HR $\left.>100 \cdot \mathrm{min}^{-1}\right)$, bradycardia (HR $<60 \cdot \mathrm{min}^{-1}$ ), diaphoresis (skin pallor and beads of sweat on forehead), respiratory depression (defined below), nausea and vomiting (as reported by the patient), and blurred vision. Muscle rigidity was evaluated by observation, palpation and questioning of the patient by the research nurse or investigator.

Patients were discontinued from the study if any of the following occurred: respiratory rate $<8 \mathrm{bpm}$ for $>$ five minutes; $\mathrm{PaCO}_{2}$ of $255 \mathrm{mmHg}$; excessive sleepiness or lack of responsiveness to verbal stimulation; request by the patient, primary physician, or investigator; inadequate pain relief (patient requested to be discontinued from the study, stating pain as the reason); $\mathrm{SpO}_{2}<86 \%$ with no return to baseline after minor stimulation. Supplemental oxygen was not utilized after subjects left the PACU unless the $\mathrm{SpO}_{2}$ decreased to $<86 \%$ at which time the patient was discontinued from the study. The $\mathrm{PaCO}_{2}$ was measured by arterial blood gas analysis only if the patient's respiratory rate was $<8 \mathrm{bpm}$ for $>$ five minutes.

Medical management for respiratory depression (respiratory rate $<8 \mathrm{bpm}$ ) consisted of: removal of patch, verbal and physical stimulation and observation, use of naloxone (incremental $i v$ doses of 80-100 $\mu \mathrm{g}$ ), and/or the use of other appropriate medical intervention. Study personnel continued to monitor the patient as before for at least $12 \mathrm{hr}$ after removal of the patch.

Five millilitres of blood were drawn preoperatively, then at 12 and $24 \mathrm{hr}$ after patch placement for serum fentanyl assay. The blood was immediately placed on ice. Within one hour of collection, the blood was centrifuged for $15 \mathrm{~min}$ at $1000 \mathrm{G}$ to separate the plasma. The plasma was then frozen at $-20^{\circ} \mathrm{C}$ and serum fentanyl concentrations were determined by RIA (radioimmunoassay). The lower limit of the assay used was 0.05 $\mathrm{ng} \cdot \mathrm{ml}^{-1}{ }^{10,11}$ The limits of quantitation and detection of the assay were 0.20 and $0.05 \mathrm{ng} \cdot \mathrm{ml}^{-1}$, respectively. The variability in quality-control recovery was less than $5 \%$. 
Efficacy of the response to the fentanyl patch was evaluated by analgesic assessment scales, number of doses and dose of ketorolac, and number of drop-outs in each treatment group.

\section{Statistical analysis}

Statistical analysis was carried out using PCSOLVE software (Pacific Crest Software, Inc., Seattle, Wash.) Patient demographics were analyzed using the Student's $t$ test. Vital signs and pain scores were analyzed using repeated measures ANOVA followed by $t$ test with Bonferroni's correction where appropriate. The amount of ketorolac used was analyzed using the Mann-Whitney $U$ test. The frequency of side effects and dropout rates were analyzed with the chi-square test. $P$ values of $<0.05$ were considered statistically significant. All values are expressed as mean \pm standard error of the mean (SEM).

\section{Results}

The two groups did not differ with regard to age, race, weight, height or ASA status (Table I). There was no difference between the groups in the types of surgical procedures performed or in the mean duration of the procedure (156 $\pm 28 \mathrm{~min}$ for group A vs $162 \pm 31 \mathrm{~min}$ for group $\mathrm{P}$ ). There was also no difference between the two groups in the amount of intraoperative sufentanil $\left(0.87 \pm 0.3 \mu \mathrm{g} \cdot \mathrm{kg}^{-1}\right.$ ps $\left.0.95 \pm 0.32 \mu \mathrm{g} \cdot \mathrm{kg}^{-1}\right)$ or recovery room morphine given $\left(26.9 \pm 4.3 \mu \mathrm{g} \cdot \mathrm{kg}^{-1}\right.$ vs 30.1 $\left.\pm 3.8 \mu \mathrm{g} \cdot \mathrm{kg}^{-1}\right)$.

Group A patients used less ketorolac for supplemental analgesia for the $36 \mathrm{hr}$ postoperatively. The median number of doses of demand $i m$ ketorolac was two doses for group A vs three doses for group $\mathrm{P}$ $(P<0.05)$. The median total demand im ketorolac (excluding the intraoperative dose) was $60 \mathrm{mg}$ for group $\mathrm{A}$ and $90 \mathrm{mg}$ for group $\mathrm{P}(P<0.05)$. There was no difference between serum fentanyl concentrations for the active patch group at 12 and $24 \mathrm{hr}$ after patch placement (Figure 2).

Also, there was no difference between the groups with respect to systolic and diastolic arterial blood pressures. Heart rates were lower for group $A$ than for group $\mathrm{P}$ at 8,16 , and $36 \mathrm{hr}$ after patch placement (Figure 3a). Respiratory rates were lower for group A at 8 and $12 \mathrm{hr}$ than for group $\mathrm{P}$ (Figure $3 \mathrm{~b}$ ). There were no differences between the two groups with respect to $\mathrm{SpO}_{2}$ (Figure 3a).

Visual analog pain scores $(100 \mathrm{~mm})$ were lower $(P<0.05)$ for group A at 8, 12, 16 and $24 \mathrm{hr}$ after patch placement (Figure 4). More patients $(P<0.05)$ in group $\mathrm{P}(10,21.7 \%)$ dropped out of the study due to inade-

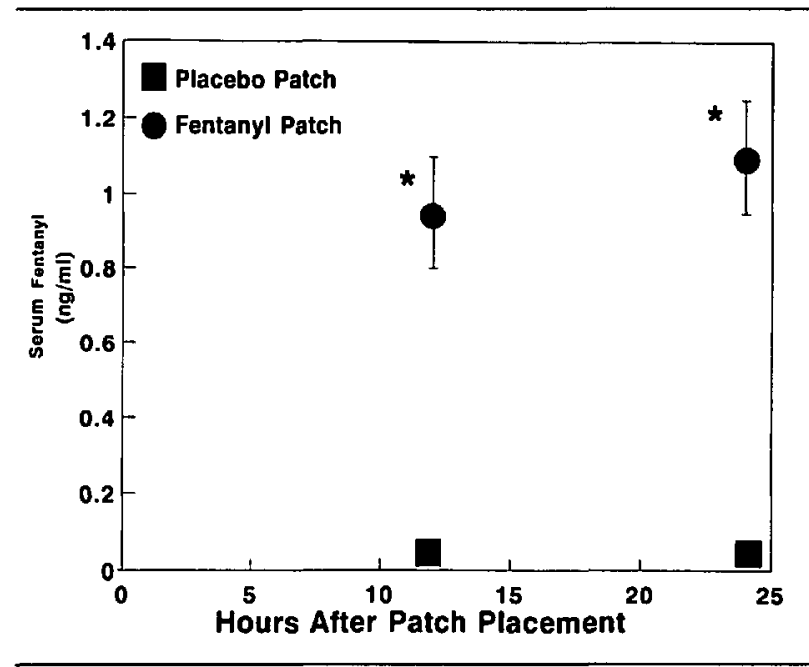

FIGURE 2 Serum fentanyl concentrations for group A and group $\mathrm{P}$ (mean $\mathrm{ng} / \mathrm{ml} \pm \mathrm{SEM}$ ).

${ }^{\star} P<0.0001$ compared with placebo patch. The patch was removed at $24 \mathrm{hr}$.

\section{Cardiorespiratory Variables}
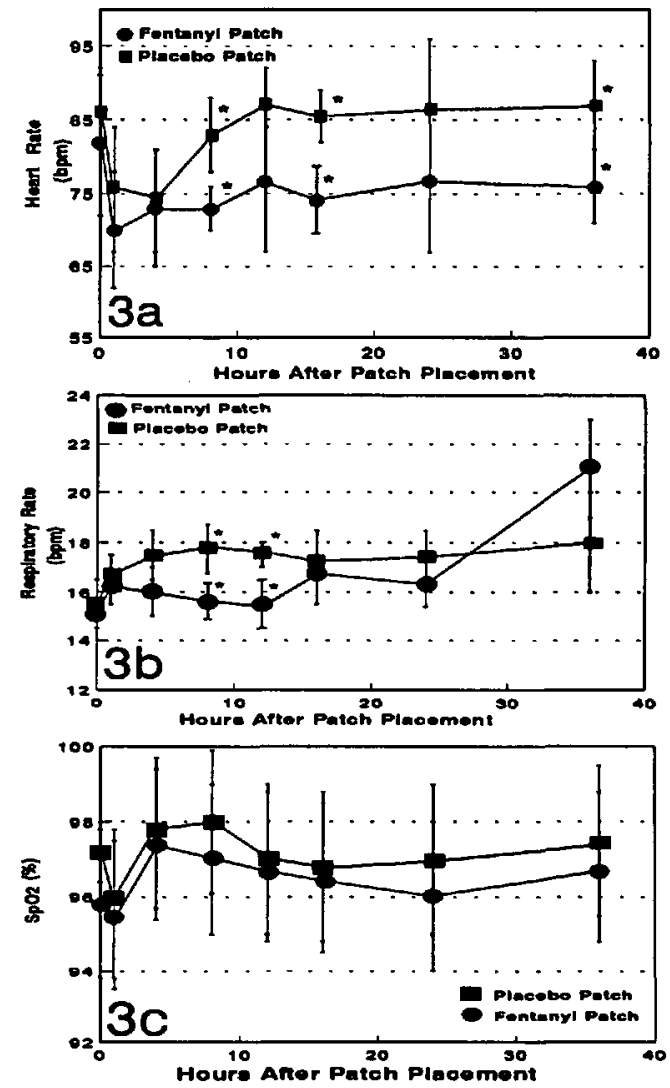

FIGURE 3 Cardiorespiratory variables.

3a Heart rates for groups $\mathrm{A}$ and $\mathrm{P}$ (mean bpm \pm SEM). ${ }^{*} P<0.05$.

$3 \mathrm{~b}$ Respiratory Rate for groups $A$ and $P$ (mean breaths per minute \pm SEM). ${ }^{*} P<0.05$. The patch was removed at $24 \mathrm{hr}$.

$3 \mathrm{C}$ Oxygen saturation $\left(\mathrm{SpO}_{2}\right)$ for the active and placebo patch group (mean percent $\pm S E M$ ). 


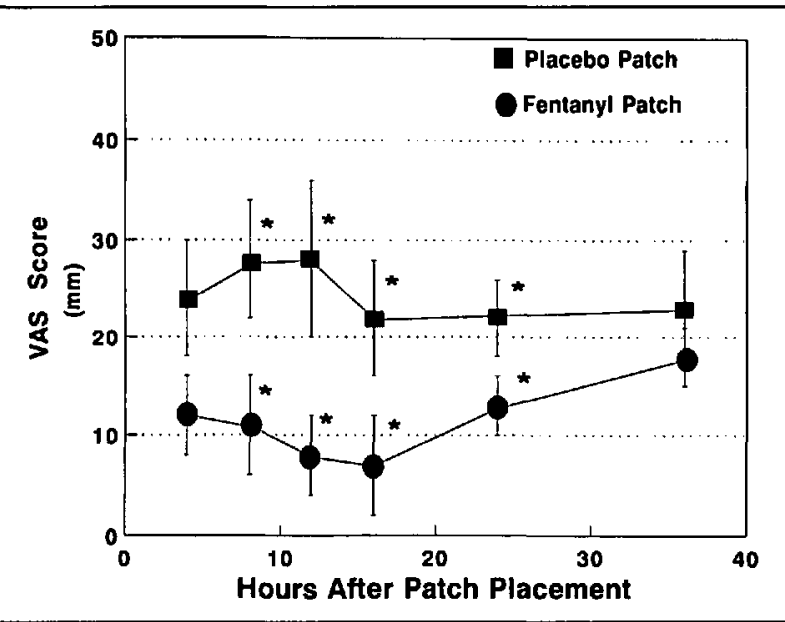

FIGURE 4 Visual Analog Scale Pain Score for the two study groups (mean millimeters \pm SEM).

* $P<0.05 .0 \mathrm{~mm}$ end of scale defined as "no pain" and $100 \mathrm{~mm}$ end of scale defined as "worst possible pain."

quate analgesia than in group A $(2,4.3 \%$, Table II). However, there was no difference in total drop-out rate between the two groups. Inadequate analgesia was defined as VAS pain scores consistently $>\mathbf{2 0}$ and the patient requesting to be discontinued from the study due to lack of analgesia. Patients discontinued from the study for inadequate analgesia were placed on a regimen of iv PCA morphine and were monitored for the remainder of the $36 \mathrm{hr}$ without any report of respiratory depression.

There was a greater incidence of pruritus in group A. There was a greater incidence of patients reporting pain as a problem in group P. There were no differences in the other side effects studied (Table III). Although five patients in group A had a decrease in $\mathrm{SpO}_{2}$ (Table III), no patient was terminated from the study for a persistently low $\mathrm{SpO}_{2}$, and only one patient from group $\mathrm{A}$ was discontinued due to a low respiratory rate (Table II). The other five patients in Table III responded to encouragement to deep breathe or low flow supplemental oxygen by nasal cannula. They were not discontinued from the study.

\section{Discussion}

Previous investigators have reported the successful use of transdermal fentanyl for postoperative analgesia with some reporting respiratory depression., ${ }^{6,12-19}$ However, they all employed opioids as the supplemental analgesic. Recently, Sandler ${ }^{5}$ and Stanski ${ }^{6}$ proposed that investigation into the use of transdermal fentanyl as a component of a multimodal analgesic system (i.e., in conjunction with a nonsteroidal antiinflammatory drug) because it may provide an effective
TABLE II Summary of Study Drop-outs

\begin{tabular}{lccc}
\hline & Group A & Group $P$ & $P$ \\
\hline Inadequate & & & \\
Analgesia & 2 & 10 & $<0.05$ \\
Hypotension & 2 & 0 & NS \\
Low $\mathrm{SpO}_{2}$ / Resp Rate & 1 & 0 & NS \\
Return to OR & 1 & 0 & NS \\
Laryngospasm & 1 & 0 & NS \\
Abdominal Cramps & 0 & 2 & NS \\
Total Drop-outs & $7 / 46$ & $12 / 46$ & NS \\
\hline
\end{tabular}

TABLE III Summary of Adverse Events

\begin{tabular}{lccc}
\hline & $\begin{array}{c}\text { Group } A \\
n=42\end{array}$ & $\begin{array}{c}\text { Group } P \\
n=42\end{array}$ & $P$ \\
\hline Nausea & $25(60 \%)$ & $20(48 \%)$ & NS \\
Vomiting & $11(26 \%)$ & $7(17 \%)$ & NS \\
Itching & $8(19 \%)$ & $1(2 \%)$ & $<0.05$ \\
Low $\mathrm{SpO}_{2}$ & $5(12 \%)$ & $1(2 \%)$ & NS \\
Respiratory Rate $<9$ & $4(9 \%)$ & $2(4 \%)$ & NS \\
Somnolence & $1(2 \%)$ & $0(0 \%)$ & NS \\
Hypertension & $0(0 \%)$ & $0(0 \%)$ & NS \\
Hypotension & $4(9 \%)$ & $1(2 \%)$ & NS \\
Tachycardia & $2(4 \%)$ & $3(7 \%)$ & NS \\
Bradycardia & $2(4 \%)$ & $1(2 \%)$ & NS \\
Anxious & $2(4 \%)$ & $6(14 \%)$ & NS \\
Pain & $3(7 \%)$ & $20(48 \%)$ & $<0.05$ \\
Muscle cramps & $0(0 \%)$ & $2(4 \%)$ & NS \\
Abdominal cramps & $0(0 \%)$ & $4(9 \%)$ & NS \\
Difficulty voiding & $0(0 \%)$ & $2(4 \%)$ & NS \\
\hline
\end{tabular}

postoperative analgesic regimen. The present study was conducted to test this hypothesis and employed ketorolac as the supplemental analgesic. In this study, the active patch patients used less adjunctive medication and achieved superior pain scores than did patients in the placebo patch group. This might have been predicted and is consistent with the majority of previous studies conducted using opioids as the supplemental analgesic. ${ }^{12-19}$

There were no differences in blood pressures between the two groups although there was a decrease in heart rate in the active patch group during the 8 th, 16th, and 36th hr observations. This is consistent with known effects of opioids on heart rate during effective analgesia. ${ }^{20}$ The lower respiratory rate for the active patch group is a predictable response to transdermal fentanyl and is consistent with previous studies. ${ }^{12,16,18,19}$ Gourlay et al. reported that three of 13 patients required reduction in the transdermal fentanyl dose due to bradypnea while one required an increased dose due to inadequate pain relief using a $75 \mu \mathrm{g} \cdot \mathrm{hr}^{-1}$ system initially. ${ }^{16}$ 
Coupling a lower dose transdermal fentanyl system with a nonsteroidal anti-inflammatory analgesic may result in less respiratory depression than adding more opioid analgesia to the patch. No patient was discontinued from the study due to low respiratory rate (although one was removed due to a low $\mathrm{SpO}_{2}$ ). The data could be interpreted as result of a higher respiratory rate for group $\mathrm{P}$ due to less effective analgesia. The respiratory rate in group A was less than that in group $\mathrm{P}$ at the time of peak serum fentanyl concentrations and then increased after the patch was removed (Figure 3b).

There was no difference in mean oxygen saturation $\left(\mathrm{SpO}_{2}\right)$ between groups $\mathrm{A}$ and $\mathrm{P}$. One patient in group $A$ was removed from the study because of a low respiratory rate although the $\mathrm{SpO}_{2}$ was acceptable. No patient in group $\mathrm{P}$ was removed either for low respiratory rate or low oxygen saturations reflecting the highly variable patient sensitivity and response to opioids. ${ }^{21}$

One important finding of this study was the lower visual analog pain scores in group A (Figure 4). The smaller difference between active and placebo patch group pain scores in previous studies may have resulted from the use of opioid supplemental analgesia. Furthermore, the opioid supplement was given using patient-controlled analgesia allowing the patient to titrate to his or her own pain relief and, therefore, making pain scores less distinguishable. ${ }^{18,21}$ In the present study, this difference is more predictable by the use of fixed-dosage $i m$ ketorolac as the adjunct analgesia. The study was designed to achieve cquivalent analgesia in all patients following surgery. Intraoperative sufentanil and postoperative im morphine were titrated liberally since adequate serum fentanyl concentrations were not anticipated to be reached for several hours after surgery.

In a previous study after knee surgery, 8 of 28 (28.6\%) patients had complete relief with transdermal fentanyl $\left(75 \mu \mathrm{g} \cdot \mathrm{hr}^{-1}\right)$ alone ${ }^{13}$ whereas, in the present study, 10 of $42(23.8 \%)$ patients in the active patch group completing the study did not request analgesic supplementation. This suggests that the transdermal fentanyl system in this dose delivery is not adequate "stand alone" analgesia for the majority of patients in the postoperative period.

More patients receiving ketorolac alone (placebo patch) were discontinued from the study due to poor postoperative analgesia than in the active patch group $(21.7 \%$ vs $4.3 \%)$. The overall drop-out rate, however, was not different $(15.2 \%$ vs $26.1 \%)$ because of other reasons for drop-out among the active patch group (Table II).

A large number of patients reported nausea and vomiting in both groups, but there was no difference between groups. This is consistent with most previous studies ${ }^{14,16,17,19}$ although a lower incidence of nausea and vomiting might have been expected in the control, ketorolac only, group. Pruritus was more prevalent with the active fentanyl patch group, a well-documented side effect of opioids and consistent with some reports. ${ }^{14,16,19}$

Mean serum concentrations are difficult to compare with previous studies using different patch sizes and delivery rates. Holley and van Steenis showed mean plateau serum fentanyl concentrations at $24 \mathrm{hr}$ of $2.0 \pm 0.7 \mathrm{ng} \cdot \mathrm{ml}^{-1}$ for the TTS Fentanyl 100 and $1.5 \pm 0.5 \mathrm{ng} \cdot \mathrm{ml}^{-1}$ for TTS Fentanyl $75^{14}$ compared with mean concentrations of $0.957 \pm 0.12 \mathrm{ng} \cdot \mathrm{ml}^{-1}$ and $1.127 \pm 0.18 \mathrm{ng} \cdot \mathrm{ml}^{-1}$ for the $30 \mathrm{~cm}^{2}$ and $40 \mathrm{~cm}^{2}$ fentanyl patches at 12 and $24 \mathrm{hr}$ respectively in the present study.

Although $i v$ injection of ketorolac is more acceptable than im injection to patients, this route was not approved by the FDA until after the study had begun. Although ketorolac has a reasonable safety profile, its effectiveness is limited due to an analgesic ceiling. $22-24,25$ The concurrent use of the two medications in lower doses may have the following advantages: lower risk of overdose from opioids, analgesic potency of opioids preserved with an opioid-sparing effect. ${ }^{26}$

Therapeutic steady-state plasma concentrations are achieved with TTS-Fentanyl within four to eight hours of application of the fentanyl system. ${ }^{12-15}$ Therapeutic serum concentrations are observed up to $12 \mathrm{hr}$ after removal of the transdermal system. ${ }^{14,16,17}$ The steady rate of opioid release from the transdermal fentanyl system has advantages and disadvantages. A constant drug level within a therapeutic range may eliminate high peak serum concentrations associated with side effects and troughs associated with inadequate analgesia. Fentanyl has a predictable onset of action and elimination half-time which makes it appropriate for continuous absorption. ${ }^{27}$

Plasma concentrations of $1-2 \mathrm{ng} \cdot \mathrm{ml}^{-1}$ usually provide a therapeutic serum level for adequate analgesia. ${ }^{21}$ It may take from six to eight hours to achieve therapeutic serum fentanyl concentrations and up to $24 \mathrm{hr}$ to reach peak levels with the transdermal fentanyl system. ${ }^{14,28}$ Once a steady state is reached, transdermal fentanyl provides a constant drug level and should decrease the need for injections and reduce the need for expensive infusion devices. Conversely, the pre-set delivery rate of the patch may achieve drug levels in the therapeutic range for certain individuals while underdosing or overdosing others. Furthermore, during the postoperative period, analgesia needs are variable and rapid adjustments using such a system are difficult. The 
transdermal delivery of fentanyl, therefore, served as a "background" infusion of opioid analgesia in this study. Analgesia for pain "peaks" was provided by multimodal therapy with the addition of ketorolac.

In summary, the new transdermal fentanyl delivery system (FTDS) has high efficacy when used in low dose with ketorolac tromethamine for the control of postoperative pain. The addition of a potent, injectable nonsteroidal anti-inflammatory may allow a lower dose patch to be administered and a reduction of opioid side effects. If transdermal fentanyl is to be used extensively after surgery, it will likely be in the form of "background" analgesia with supplementation from another form of analgesia. Since the safety of this system has yet to be established, we recommend that transdermal fentanyl is employed for acute pain only in a monitored medical environment.

\section{References}

1 Bailey PL, Stanley TH. Package inserts and other dosage guidelines are especially useful with new analgesics and new analgesic delivery systems (Editorial). Anesth Analg $1992 ; 75$; 873-5.

2 Sandler $A$. Transdermal fentanyl: acute analgesic clinical studies. J Pain Symptom Manage 1992; 7: S27-35.

3 Wright C. Medical Officer Review, NDA \#19813, Alza Corp. TTS Fentanyl (transdermal therapeutic system), Volume 2, Pharmacokinetics \& Pharmacodynamics, June 1990, obtained via Freedom of Information Act of Congress.

4 Wright C. Medical Officer Review, NDA \#19813, Alza Corp. TTS Fentanyl (transdermal therapeutic system), Volume 4, Safety, May 1990, obtained via Freedom of Information Act of Congress.

5 Duragesic (fentanyl transdermal system) Package Insert, January 1996.

6 Miguel R, Kreitzer JM, Reinhart DJ, et al. Postoperative pain control with a new transdermal fentanyl delivery system. A multicenter trial. Anesthesiology 1995; 83: 470-7.

7 Fiset P, Cobane C, Browne S, Brand SC, Shafer SL. Biopharmaceutics of a new transdermal fentanyl device. Anesthesiology 1995; 83: 459-69.

8 Sandler $A N$, Baxter $A D$, Katz J, et al. A double blind, placebo-controlled trial of transdermal fentanyl after abdominal hysterectomy. Anesthesiology 1994; 81: 1169-80.

9 Stanski DR. Different modes of administration iv vs nasal $v s$ patch. American Society of Anesthesiologists Annual Review Course Lectures, San Fransisco, Calif., 1994: \#252, 1-3.

10 Michiels $M$, Hendricks $R$, Heykants J. A sensitive radioimmunoassay for fentanyl. Plasma levels in dogs and man. Eur J Clin Pharmacol 1977; 12: 153-8.
11 Schüttler J, White PF. Optimization of the radioimmunoassay for measuring fentanyl and alfentanil in human serum. Anesthesiology 1984; 61: 315-20.

12 Caplan RA, Ready LB, Oden RV, Matsen FA III, Nessly $M L$, Olsson GL. Transdermal fentanyl for postoperative pain management. A double-blind placebo study. JAMA 1989; 261: 1036-8.

13 Latasch $L$, Lüders $S$. Transdermal fentanyl against postoperative pain. Acta Anaesthesiol Belg 1989; 40: 113-8.

14 Holley FO, pan Steennis C. Postoperative analgesia with fentanyl: pharmacokinetics and pharmacodynamics of constant-rate $i p$ and transdermal delivery. $\mathrm{Br}$ J Anaesth 1988; 60: 608-13.

15 Gourlay GK, Kowalski SR, Plummer JL, Cherry DA, Gaukroger $P$, Cousins MJ. The transdermal administration of fentanyl in the treatment of postoperative pain: pharmacokinetics and pharmacodynamic effects. Pain 1989; 37: 193-202.

16 Gourlay GK, Kowalski SR, Plummer JL, et al. The efficacy of transdermal fentanyl in the treatment of postoperative pain: a double-blind comparison of fentanyl and placebo systems. Pain 1990; 40: 21-8.

17 Duthie DJR, Rowbotham DJ, Wyld R, Henderson PD, Nimmo WS. Plasma fentanyl concentrations during transdermal delivery of fentanyl to surgical patients. $\mathrm{Br}$ J Anaesth 1988; 60: 614-8.

18 Rowbotham DJ, Wyld R, Peacock JE, Duthie DJR, Nimmo WS. Transdermal fentanyl for the relief of pain after upper abdominal surgery. Br J Anaesth 1989; 63: 56-9.

19 Lebmann KA, Einnolf $C$, Eherlein $H-J$, Nagel $R$. Transdermal fentanyl for the treatment of pain after major urological operations. A randomized doubleblind comparison with placebo using intravenous patient-controlled analgesia. Eur J Clin Pharmacol 1991; 41: 17-21.

20 Murat I, Levron J-C, Berg A, Saint-Maurice C. Effects of fentanyl on baroreceptor reflex control of heart rate in newborn infants. Anesthesiology 1988; 68: 717-22.

21 Gourlay GK, Kowalski SR, Plummer JL, Cousins MJ, Armstrong PJ. Fentanyl blood concentration - analgesic response relationship in the treatment of postoperative pain. Anesth Analg 1988; 67: 329-37.

22 Power I, Noble DW, Douglas E, Spence AA. Comparison of $\mathrm{i} . \mathrm{m}$. ketorolac tromethamine and morphine sulfate for pain relief after cholecystectomy. $\mathrm{Br} \mathrm{J}$ Anaesth 1990; 65: 448-55.

23 Powell H, Smallman JMB, Morgan M. Comparison of intramuscular ketorolac and morphine in pain control after laparotomy. Anaesthesia 1990; 45: 538-42.

24 O'Hara DA, Fragen RJ, Kinzer $M$, Pemberton $D$. Ketorolac tromethamine as compared with morphine 
sulfate for treatment of postoperative pain. Clin

Pharmacol Ther 1987; 41: 556-61.

25 Abramowicz $M$. Ketorolac tromethamine. Med Lett Drugs Ther 1990; 32: 79-81.

26 Ready LB, Brown CR, Stablgren LH, et al. Evaluation of intravenous ketorolac administered by bolus or infusion for treatment of postoperative pain.

Anesthesiology 1994; 80: 1277-86.

27 Tum SI. Transdermal therapeutic systems and rate controlled drug delivery. Med Prog Technol 1989; 15:

47-52.

28 Plezia PM, Kramer TH, Linford J, Hameroff SR.

Transdermal fentanyl: pharamacokinetics and preliminary clinical evaluation. Pharmacotherapy $1989 ; 9: 2-9$. 